Supplement of Biogeosciences Discuss., 12, 7449-7490, 2015

http://www.biogeosciences-discuss.net/12/7449/2015/

doi:10.5194/bgd-12-7449-2015-supplement

(C) Author(s) 2015. CC Attribution 3.0 License.

(c) (i)

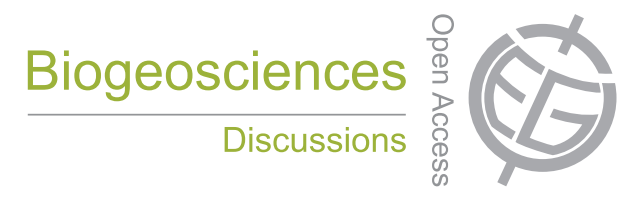

Supplement of

\title{
Detecting methane ebullition on thermokarst lake ice using high resolu- tion optical aerial imagery
}

\section{P. R. Lindgren et al.}

Correspondence to: P. R. Lindgren (pregmi@alaska.edu)

The copyright of individual parts of the supplement might differ from the CC-BY 3.0 licence. 
Figure SI. Image object hierarchy used in the objected oriented classification technique developed to identify bubble patches on early winter lake ice. Image segmentation is performed in each level and image objects are classified. In the first level, segmentation is performed on the whole lake image to identify Lake Shore and Lake. In the second level, only the Lake region is segmented and image objects derived from the Lake are classified into different lake ice characteristics. This process continues as it proceeds towards lower and finer classification levels until Bubbles are identified in the lake ice.

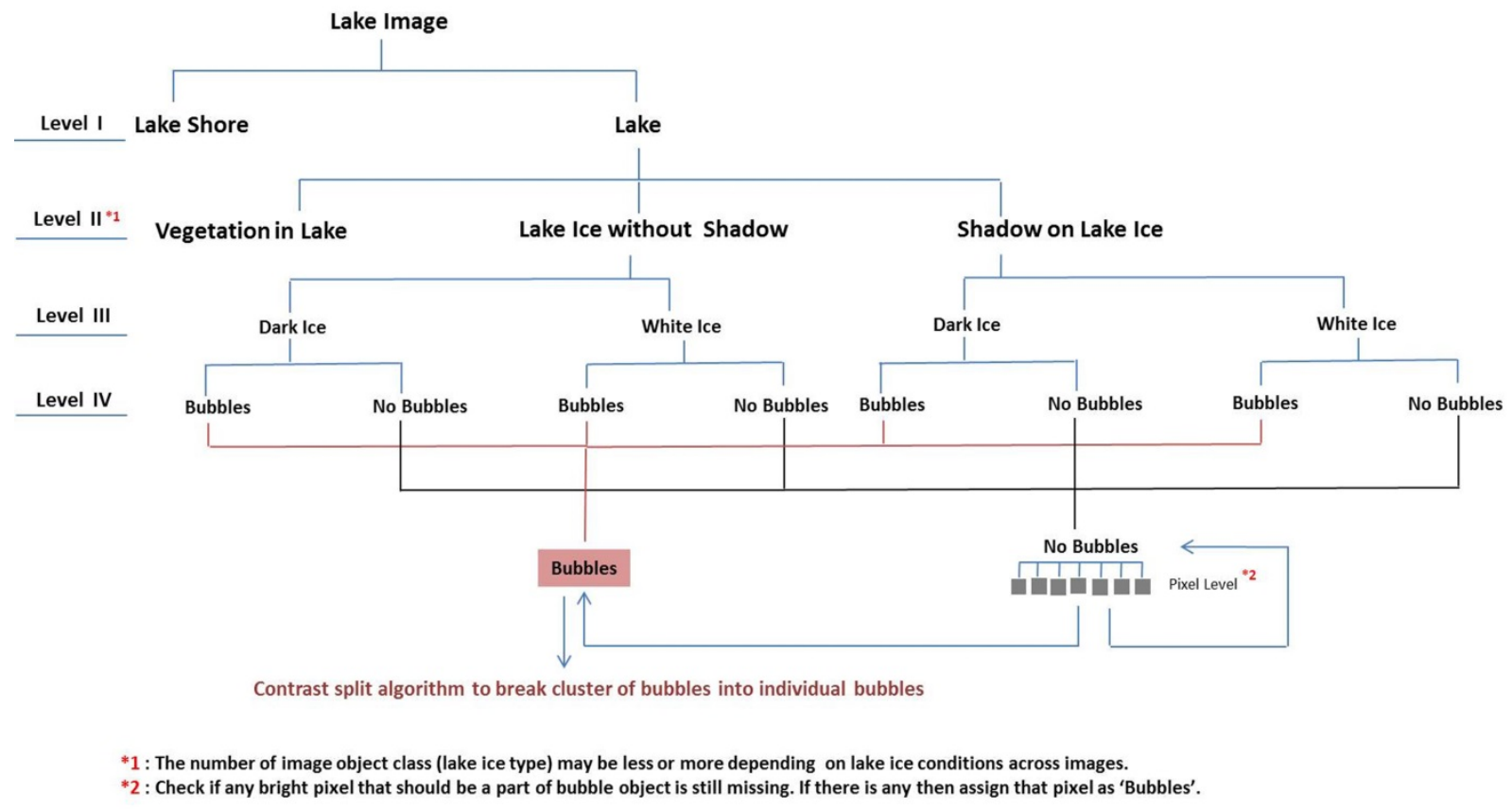


Table SI. Tukey's Honestly Significant Difference (HSD) test showing significant difference (with p-values* $<0.05$ at 95\% confidence interval) between bubble patches identified in aerial images as C- and A-type seeps, Hotspot and A-type seeps, and Hotspot and B-type seeps for 2011 and 2012.

\section{Year 2011}

\section{$95 \%$ Confidence Interval}

\begin{tabular}{lllll}
\hline Seeps & Mean Difference & $\begin{array}{l}\text { Lower } \\
\text { Bound }\end{array}$ & $\begin{array}{l}\text { Upper } \\
\text { Bound }\end{array}$ & p-values \\
\hline B-A & -6.43 & -18.89 & 6.03 & 0.54 \\
C-A $^{*}$ & -20.28 & -37.14 & -3.40 & $0.01^{*}$ \\
Hotspot-A $^{*}$ & -32.73 & -41.85 & -23.61 & $0^{*}$ \\
C-B & -13.84 & -32.32 & 4.63 & 0.21 \\
Hotspot-B & -26.30 & -38.13 & -14.48 & $0.00^{*}$ \\
Hotspot-C & -12.45 & -28.87 & 3.95 & 0.21
\end{tabular}

Year 2012

$95 \%$ Confidence Interval

\begin{tabular}{lllll}
\hline Seeps & & Lower & Upper & \\
& Mean Difference & Bound & Bound & p-values \\
\hline B-A & -6.41 & -12.95 & 0.13 & 0.06 \\
C-A $^{*}$ & -15.36 & -23.84 & -6.88 & $0.00^{*}$ \\
Hotspot-A $^{*}$ & -13.51 & -17.98 & -9.05 & $0.00^{*}$ \\
C-B $^{*}$ & -8.95 & -18.67 & 0.78 & 0.08 \\
Hotspot-B $^{*}$ & -7.10 & -13.62 & -0.58 & $0.02^{*}$ \\
Hotspot-C $^{*}$ & 1.85 & -6.62 & 10.31 & 0.94
\end{tabular}


Figure SII. Photo of an ice block cross-section in April of 2013 from an ebullition seep on Goldstream L., Fairbanks, Alaska. The bubble size variation traces dynamics of the point source emission during winter. Vertically-oriented, circular and flat layers of methane bubbles separated by clear ice indicate highly episodic nature of ebullition. Varying size of bubbles and periods of ice growth with no bubbling confirm previous bubble-trap observations that bubbling is episodic rather than constant over time. Black marks on the ruler have 10-cm spacing.

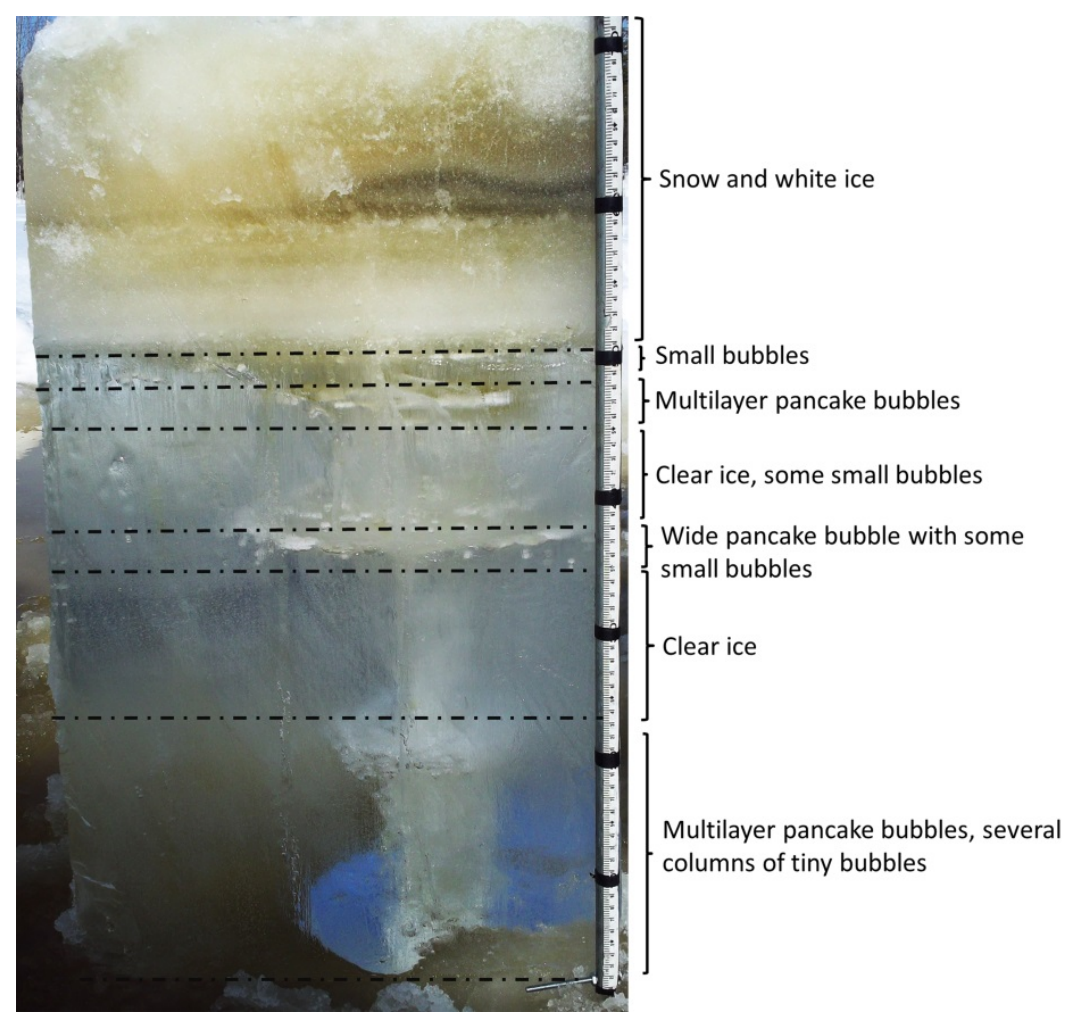


Figure SIII. Ice-free Hotspot location map of Goldstream L. overlaid on a natural color composite (red, green and blue bands) image acquired using a UAV on 14 October, 2012.

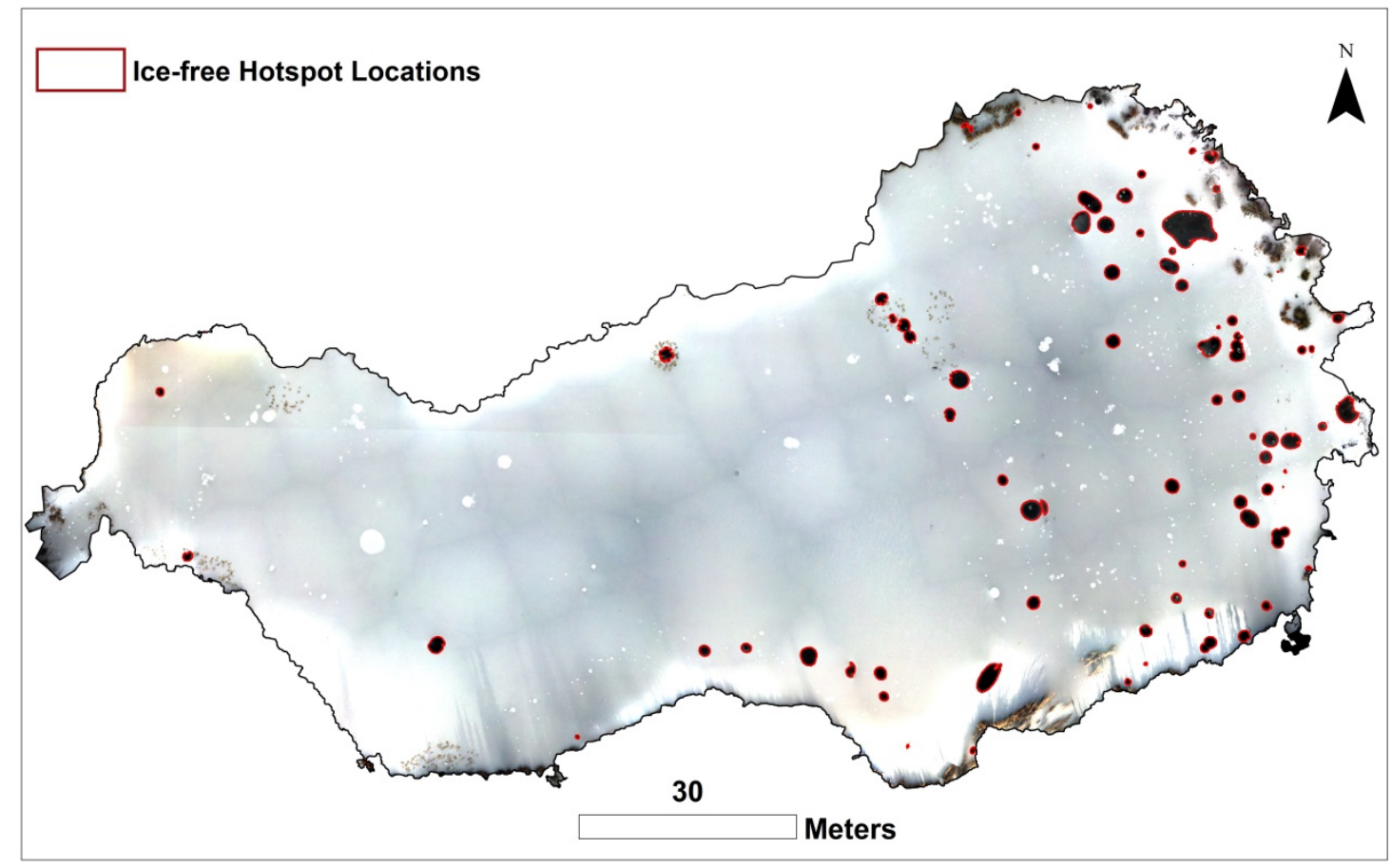

